\title{
TIME SERIES MODELLING ALGORITHM FOR PREDICTION OF EARTHQUAKES IN NEPAL
}

\author{
Sumita Mukherjee ${ }^{1}$, Prinima Gupta², Felix Musau ${ }^{3}$ \\ ${ }^{1}$ Research Scholar, Manav Rachna University, Faridabad, Haryana, India \& Director, University Advancement \& \\ Internationalization, Riara University, Nairobi, Kenya \\ ${ }^{2}$ Associate Professor, Manav Rachna University, Faridabad, Haryana, India \\ ${ }^{3}$ Dean, Computing Science, Riara University, Nairobi, Kenya \\ Email: ${ }^{1}$ smukherjee@riarauniversity.ac.ke, ${ }^{2}$ prinima@mru.edu.in, ${ }^{3} f m u s u a u @$ riarauniversity.ac.ke
}

\begin{abstract}
The regression analysis, time series, logistic models, neural networks, the Bayesian belief network, and decision trees, are associated with big data, data mining research, algorithm not only to help forecasting but also used for prediction of earthquake. Seismic wave propagation in the form of the earth's crust, is responsible for earthquake occurrences and depends on associated variables and is to be determined from records obtained and received form Nepal Meteorology Department having different factors like depth, magnitude, location, latitude, longitude etc. by mining methods and results are then evaluated thoroughly. This paper focuses on implication of seismic pattern, trends, association, comparison of earthquake occurrences on statistical data, using time series mining. This paper also studies and correlates various factors with the seismic activity for predicting occurrences of earthquake by developing machine learning models through visualizing time series pattern. It recognizes a strong pattern and orchestrates earthquake prediction. The machine learning method used Python programming to generate accurate graphs neural networks modelling and explains overfitting, stationarity and parsimony features for earthquake prediction. Data is in a non-linear relationship uses curved fitting regression. In this study, the comparative results of seismic time series are analyzed at testing point and prediction point. To keep down the destruction by earthquake expert decision systems by Neural network can be developed only using seismic time series analysis having different factors which can be a good study and explanation to develop an algorithm using the following methodology Auto regression (AR), Moving Average (MA), Seasonal Autoregressive Integrated Moving-Average (SARIMA).
\end{abstract}

Keywords: Data Mining, Seismic wave, Neural Network, Time series, Non-Linear relation

\section{Introduction}

If we want to mention any collective experience, earthquakes are one disaster comes to the mind. All institutions related to meteorology and people of any country have long engagement in earthquake science through the reporting, collection, and analysis either through individual or team efforts. Time Series data mining plays a vital role to track, map, and analyse the details of small or large destructive earthquake ruptures. The same data mining is also evasive and portraits that how the earthquake is linked to rupture process, analyses detailed data from close to the event. Each report brings out the location of the happening then is converted to latitude-longitude coordinates followed by mapping of data. The initial prediction of earthquake depends on the parameters like time, magnitude and location. The earth's crust displacement part in comparison to other part of earth like mantle, plates have a variable speed. With these three parameters and the rocks atmosphere throws resistance to the cracks and piles up tension in the environment. Before the attack of the earthquake, it is advisable to minimize the traumatic state of mind, destruction of infrastructure and minimize the losses of lives among people. Big data plays an important role which must be accurate and properly filtered for prediction of earthquake. Based on the quantification of seismic activity the occurrences of earthquake are determined in terms of area, size, type, frequency. As a measure, the liberated energy, magnitude is generated during earthquake though there is no means to measure the energy directly. To predict future values based on values observed earlier or before the time series model includes a huge number of observations which are well- defined data items ordered in equal space or equal time. If the gathered data happens only once or irregular in nature are not categorized as a time series data. An observed time series are categorized into three types as follows:

- The Seasonal component: Seasonal data are systematic or regular movements of data.

- The Trend component: Trend data mean by long- term fluctuations and the irregular data mean by unsystematic or short-term fluctuations.

- $\quad$ The Residual Component: The residual time series after the trend-cycle and the seasonal components (including the effects of calendar) have been initiated, endangered and deleted of a time series component reading. 
It also coincides to the fluctuations of the series at a high frequency. Historical information in figure 1 appears to the left of the vertical line and represents the data that the algorithm uses to create the model. The information appears to the right of the vertical line of the model represents prediction and represents the forecast.

The following Figure 1 shows a typical model for forecasting occurrences of earthquake in four different regions over time. The model that is shown in the diagram shows occurrences of earthquake for each region plotted as red, yellow, purple, and blue lines. The line for each region has two parts:

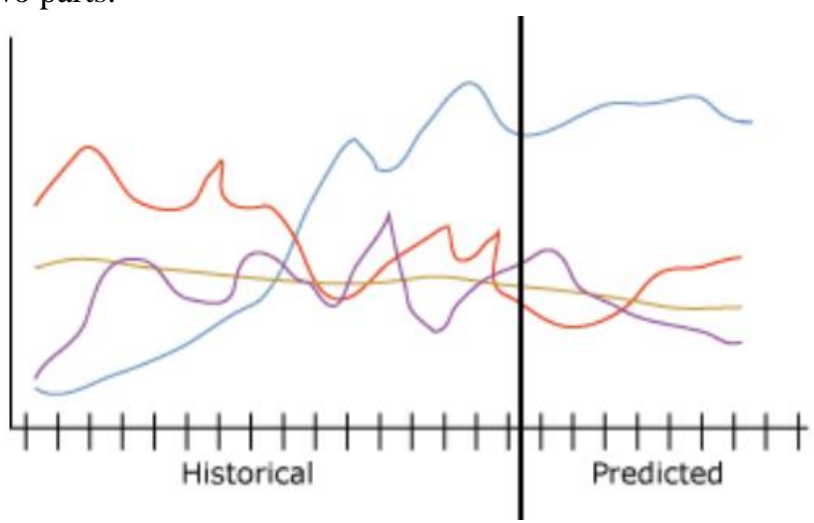

Figure 1 Showing Historical vs Predicted Earthquake

\section{Literature Review}

Based on time series modelling the occurrences and forecasting of earthquake, different zones of sensitive seismic waves are studied, clustering is demonstrated by Md. Zakir Hossain, Md Nasim Akhtar, R.B. Ahmed, considering the seismic activities are acquired by administering density-based clustering, hierarchical and k-means methods by using historical or previous data. The upcoming earthquakes in Bangladesh and its nearby areas considering the magnitude exclusively a regression model which is a predictive model isbuilt initially on data collected for forecasting [1].

As the size and occurrences of earthquake is not certain, thus the process of getting seismic sources manually is not accurate. Thus, for better efficiency the usage of databases based on past occurrences of earthquake is growing. Data mining techniques in turn use these large historical earthquake databases to capture the accurate seismic sources. For generating seismic sources automatically this paper suggests hierarchical clustering of past occurrences of earthquake [2]. To gauge the effectiveness of clustering and to find the efficiency of prediction models based on magnitude of earthquake by considering the same sources of seismic waves before and after clustering. Decision tree, SVM, and KNN are three known prediction models on which experimentation is made. Based on the experimentation, on three prediction models in this work, the decision tree delivers the most correct result and is considered the most efficient prediction model. Considering the non-spatial attributes of earthquakes when the earthquakes are clustered the most homogenous seismic sources are achieved [3][4][7].

The reviewed paper traverses the seismic events which are recorded earlier or past records of the same region and is been able to predict the seismic event of the next year having largest magnitude. Based on several data mining methods specially the analysis method on time series concepts are applied. A directory containing the events of 9,042 earthquakes are evaluated through the time series method which was recorded between (01-01-1983 and 31-12-2010) in Israel and to the nearer countries of Israel. The Geophysical Institute of Israel has helped to extract the data for research. Each earthquake records in the directory are clubbed with one of 33 seismic regions. The objective of this paper is to predict whether the earthquake having the greatest magnitude in the following year will exceed the median in the same region, having maximum yearly magnitudes [5] [6] [7]. A long-term seismic hazard which is represented by an earthquake directory shows different readings of regions having low to moderate occurrences of earthquake and estimates a uniform size. A directory of earthquakes is used as a basis for fitting appropriate models of South Asia from 1905 to 2009 for spatial distribution. The assigned independent variables are focal length, latitude and longitude and the magnitude is defined as dependent variable [8][9]. In this study, a set of analytical suites of WEKA and SPSS are used for availing data for smoothing result. A thorough analysis is made for validating all the values for independent variables and checking the consistency and error variance for the variables. Identification of predicted magnitude with actual magnitude of an earthquake occurrence has been carried out here. The correlation of the predicted output magnitude in WEKA has a higher coefficient of determination (R2) in comparison to SPSS magnitude which is reflected and correlated by the output [10][11][12].

In many real-world systems networks or graphs modelling can be used. To understand and refer the clustering networks algorithms specially graph based clustering algorithms a model has to be studied carefully. Many algorithms exist in the literature for clustering network data. The task of different researchers during evaluation is to analyze these clustering algorithms and have a comparative understanding on their qualities [13][14]. This paper argues that networks having concentrated components, such as social network evaluation methods gets biased on density heavily, but are not appropriate for other network topologies for different data sets. When the nodes are having varied data sets and not densely connected are not suitable for these topologies. Networks dealing with internets, networks associated with transportation are examples of such mentioned data sets. The hypothesis is justified by considering the data sets from real life examples [15][16]. 
This paper discusses the prediction of weak and strong earthquakes based on temporal data having seismic wave behavior. When the medium and large earthquake happen. These known patterns are observed and determined through the occurrences of weak and strong earthquakes. Chris Gray discussed the possibilities of five geophysical precursors responsible for the occurrences of earthquake and helps in prediction [17]. The case study of Indonesia region describes and reviews the statistical analysis by studying the depth and slip. The earthquakes are categorized according to statistical analysis and then the comparison is made on the years and magnitude. This paper reviews the methods of finding the occurrences of earthquake in future by implicating the model related to time series data mining principals and concepts [18].

In addition to customary statistical approaches for data mining (DM) methods are used in abundance to predict the occurrences of earthquake. This paper presents a literature review of the use of DM with time series data, focusing on short time stocks prediction. Researchers are working hard to map the model through time series for predicting the occurrences of earthquake. This paper's contribution is to provide an understanding of data mining which specifically narrates the usage of time series data and its concepts. It deals with primarily those examples which depict the occurrences of short-term earthquake prediction [19].

Summary: The most insecure and precarious natural calamity is none other than earthquake. Many algorithms have been proposed for earthquake prediction using expert systems (ES), regression analysis, machine learning technology, quantitative numerical analysis various time series methods like AR, MA, SARIMA. The main aim is to link, and study different parameter associated with earthquake like location, depth, magnitude, longitude, latitude and find a proper correlation and association on occurrences of earthquake.

The forecasting or prediction by time series is mainly the machine learning modelling for Time Series data (Date, Time, Longitude, Latitude, Depth, Magnitude etc.) for predicting future values of earthquake using Time Series modelling. This method develops a correlation among available data in serial format. A time series is modelled to find out the parameters observed using RNNs (Recurrent neural networks) which can classify the parameters in terms of seasonal patterns, trends, relation to external factors. Thus, many literature witnesses that the time series modelling is most suitable and accurate to forecast future values of series of observed data.

\section{Proposed Methodology}

Based on the summary, the need for the research on seismological occurrences is very required, therefore new algorithms, methods, tools and techniques are needed in order to predict magnitude, time and geographic location, and to understand the relationship among the parameters so to save countless human lives. Prediction of earthquake can be distinguished further from earthquake warning systems. Earthquake detection that provides a real-time warning to neighboring regions in terms of second lapse that might be very effective. Early Response Warning System is currently responsible for alerting airports, trains, fire stations, etc. the workers at coal mine are exposed to a life-threatening danger in a form of seismic events. The earthquakes of complexity nature and highly random nature however in obtaining an efficient mathematical model, the efforts are insufficient until now and thus, new methods capable of contributing to this challenge are needed.

In this work a programming layout is developed for a novel earthquakes magnitude prediction algorithm to be proposed, which is based on the big data related to seismic events in different regions of a country and is modelled as a time series using Machine Learning, specifically a network architecture based on LSTM cells. In this proposed system deep learning technique called long short-term memory with gradient descent optimization algorithms (LSTMAdaGrad) networks will predict the future earthquakes using data of past earthquakes. This has used methodology Auto regression (AR), Moving Average (MA), Seasonal Autoregressive Integrated Moving-Average (SARIMA) methods to develop a Long Short-Term Memory neural networks graph to help in developing an algorithm for prediction. The experimental result shows the better performance compare with existing algorithm like spatial temporal analysis.

This paper has discussed different time series analysis and prediction methods. Unfortunately, or maybe luckily, there is no one way to solve these kinds of problems. Along with LSTMs and RNNs (not covered in this article) methods developed in the 1960s (and some even in the beginning of the 21 st century) are still popular. This is partially related to the fact that the prediction task, like any other data-related task, requires creativity in so many aspects and definitely requires research. It is often necessary to try something different for each time series.in spite of the large number of formal quality metrics and approaches to parameters estimation. The balance between quality and cost is important even though it can be ignored. As a good example, the SARIMA model can produce spectacular results after tuning but can require many hours of time series manipulation while a simple linear regression model and can achieve more or less comparable results which can be achieved in short span of time. In this paper we have taken some selected data from big data collected of earthquake of Nepal for last five years from 2015 to 2019.These observed data is applied Time series modelling using Python language. 
Table-1 Data collected from Nepal for year 2015

\begin{tabular}{|c|c|c|c|c|c|c|c|l|}
\hline S.no & Date & $\begin{array}{c}\text { Time } \\
\text { (UTC) }\end{array}$ & $\begin{array}{c}\text { Time } \\
(\text { IST) }\end{array}$ & Latitude & Longitude & $\begin{array}{c}\text { Depth } \\
(\mathrm{KM})\end{array}$ & $\begin{array}{c}\text { Magnitu } \\
\text { de }\end{array}$ & \multicolumn{1}{|c|}{ Regions } \\
\hline 1 & $31 / 01 / 15$ & $13: 59: 43$ & $19: 29: 43$ & $28.37^{\circ} \mathrm{N}$ & $84.07^{\circ} \mathrm{E}$ & 5.0 & 10 & Pokhran, Nepal \\
\hline 2 & $22 / 01 / 15$ & $3: 42: 00$ & $9: 12: 00$ & $29.42^{\circ} \mathrm{N}$ & $81.06^{\circ} \mathrm{E}$ & 4.0 & 45 & Nepal \\
\hline 3 & $05 / 01 / 15$ & $19: 41: 00$ & $1: 11: 00$ & $29.17^{\circ} \mathrm{N}$ & $81.63^{\circ} \mathrm{E}$ & 4.6 & 10 & Nepal \\
\hline 4 & $30 / 04 / 15$ & $0: 37: 01$ & $6: 07: 01$ & $28.01^{\circ} \mathrm{N}$ & $84.65^{\circ} \mathrm{E}$ & 4.2 & 10 & $\begin{array}{l}\text { Kathmandu, Nepal, } \\
\text { Gorakhpur, India }\end{array}$ \\
\hline 5 & $29 / 04 / 15$ & $11: 27: 05$ & $16: 57: 05$ & $27.88^{\circ} \mathrm{N}$ & $85.51^{\circ} \mathrm{E}$ & 4.8 & 14 & $\begin{array}{l}\text { Northwest of } \\
\text { Nagarkot }\end{array}$ \\
\hline 6 & $29 / 04 / 15$ & $17: 16: 00$ & $22: 46: 00$ & $27.8505^{\circ} \mathrm{N}$ & $85.6739^{\circ} \mathrm{E}$ & 4.3 & 10 & $\begin{array}{l}\text { Pokhran, } \\
\text { Kathmandu }\end{array}$ \\
\hline 7 & $\begin{array}{c}27 / 04 / \text { for } \\
15\end{array}$ & $23: 20: 00$ & $4: 50: 00$ & $27.8836^{\circ} \mathrm{N}$ & $85.1996^{\circ} \mathrm{E}$ & 4.3 & 10 & $\begin{array}{l}\text { Gokarneshwor } \\
\text { BiratNagar }\end{array}$ \\
\hline 8 & $27 / 04 / 15$ & $21: 27: 00$ & $2: 57: 00$ & $27.7555^{\circ} \mathrm{N}$ & $85.6771^{\circ} \mathrm{E}$ & 4.3 & 10 & ENS of Nagarkot \\
\hline
\end{tabular}

Table-2 Data collected from Nepal for year 2016

\begin{tabular}{|c|c|c|c|c|c|c|c|c|}
\hline S.no. & Date & $\begin{array}{l}\text { Time } \\
\text { (UTC) }\end{array}$ & $\begin{array}{l}\text { Time } \\
\text { (IST) }\end{array}$ & & Longitude & $\begin{array}{l}\text { Depth } \\
\text { (KM) }\end{array}$ & $\begin{array}{l}\text { Magnitud } \\
\mathrm{e}\end{array}$ & Region \\
\hline 1 & $27 / 01 / 16$ & $14: 57: 04$ & 20:27:04 & $27.76^{\circ} \mathrm{N}$ & $85.93^{\circ} \mathrm{E}$ & 3 & 6 & $\begin{array}{l}\text { Patan, } \\
\text { Kisanganj,India }\end{array}$ \\
\hline 2 & $27 / 01 / 16$ & 14:57:09 & $20: 27: 09$ & $27.83^{\circ} \mathrm{N}$ & $85.83^{\circ} \mathrm{E}$ & 4.4 & 10 & $\begin{array}{l}\text { Patan, Nepal, Panchana } \\
\text { India }\end{array}$ \\
\hline 3 & $21 / 01 / 16$ & $19: 22: 17$ & $0: 52: 17$ & $28.08^{\circ} \mathrm{N}$ & $84.98^{\circ} \mathrm{E}$ & 4.6 & 10 & Bidur, Kathmandu, Nepal \\
\hline 4 & $15 / 01 / 16$ & $17: 04: 37$ & $22: 34: 37$ & $28.08^{\circ} \mathrm{N}$ & $84.98^{\circ} \mathrm{E}$ & 4.3 & 10 & Kathmandu,Nepal \\
\hline 5 & $15 / 01 / 16$ & $13: 05: 23$ & $18: 35: 23$ & $27.63^{\circ} \mathrm{N}$ & $86.25^{\circ} \mathrm{E}$ & 4.1 & 10 & Kathmandu,Nepal \\
\hline 6 & 09/01/16 & $17: 43: 41$ & 23:13:41 & $27.48^{\circ} \mathrm{N}$ & $86.01^{\circ} \mathrm{E}$ & 4.4 & 10 & $\begin{array}{l}\text { Kathmandu, } \\
\text { Saharanpur, India }\end{array}$ \\
\hline 7 & $04 / 01 / 16$ & 13:02:11 & $18: 32: 11$ & $27.48^{\circ} \mathrm{N}$ & $86.01^{\circ} \mathrm{E}$ & 4.1 & 10 & Nepal \\
\hline 8 & $04 / 01 / 16$ & $1: 02: 30$ & $6: 32: 30$ & $27.48^{\circ} \mathrm{N}$ & $86.01^{\circ} \mathrm{E}$ & 4.1 & 10 & Nepal \\
\hline
\end{tabular}

Table-3 Data collected from Nepal for year 2017

\begin{tabular}{|l|l|l|l|l|l|l|l|l|}
\hline S.no & & Time & Time & Latitude & Longitude & Depth & Magnitude & Regions \\
\hline 1. & $27 / 02 / 17$ & $04: 21: 27$ & $9: 51: 27$ & $27.38^{\circ} \mathrm{N}$ & $86.13^{\circ} \mathrm{E}$ & 4.7 & 10 & Kathmandu, Nepal \\
\hline & & & & & & & & $\begin{array}{l}\text { Bahunipati, } \\
\text { Karyabinayak, Patan, } \\
\text { Nepal }\end{array}$ \\
\hline 2. & $27 / 02 / 17$ & $03: 37: 21$ & $9: 07: 21$ & $27.48^{\circ} \mathrm{N}$ & $86^{\circ} \mathrm{E}$ & 4.6 & 20 & Nepal \\
\hline 3. & $04 / 02 / 17$ & $12: 13: 17$ & $17: 43: 17$ & $27.73^{\circ} \mathrm{N}$ & $86.08^{\circ} \mathrm{E}$ & 4.4 & 10 & Nepal \\
\hline 4. & $24 / 04 / 17$ & $11: 19: 26$ & $16: 49: 26$ & $27.86^{\circ} \mathrm{N}$ & $85.77^{\circ} \mathrm{E}$ & 4.2 & 10 & Nepal \\
\hline 5. & $12 / 06 / 17$ & $11: 54: 32$ & $17: 24: 32$ & $27.62^{\circ} \mathrm{N}$ & $86.1^{\circ} \mathrm{E}$ & 4.1 & 10 & Nepal \\
\hline 6. & $24 / 07 / 17$ & $04: 44: 19$ & $10: 14: 19$ & $27.56^{\circ} \mathrm{N}$ & $85.96^{\circ} \mathrm{E}$ & 4.0 & 10 & Kathmandu, Nepal \\
\hline 7. & $02 / 07 / 17$ & $1: 58: 43$ & $7: 28: 43$ & $27.38^{\circ} \mathrm{N}$ & $86.45^{\circ} \mathrm{E}$ & 4.2 & 10 & $\begin{array}{l}\text { North East of } \\
\text { Dipayal, Nepal }\end{array}$ \\
\hline 8. & $22 / 08 / 17$ & $0: 50: 26$ & $6: 20: 26$ & $29.3931^{\circ} \mathrm{N}$ & $81.1053^{\circ} \mathrm{E}$ & 4.6 & 10 &
\end{tabular}

Table-4 Data collected from Nepal for year 2018

\begin{tabular}{|c|c|c|c|c|c|c|c|l|}
\hline S. No & Date & $\begin{array}{c}\text { Time } \\
\text { (UTC) }\end{array}$ & $\begin{array}{c}\text { Time } \\
\text { (IST) }\end{array}$ & Longitude & Latitude & Magnitude & Depth & \multicolumn{2}{|c|}{ Location } \\
\hline 1 & $02 / 03 / 18$ & $5: 06: 17$ & $10: 36: 17$ & $27.7^{\circ} \mathrm{N}$ & $86.33^{\circ} \mathrm{E}$ & 4.6 & 10 & Nepal \\
\hline & & & & & & & & $\begin{array}{l}\text { Nepal-India Border Region, } \\
\text { Gadhimai }\end{array}$ \\
\hline 3 & $28 / 06 / 18$ & $4: 15: 10$ & $9: 45: 10$ & $27.96^{\circ} \mathrm{N}$ & $84.83^{\circ} \mathrm{E}$ & 4.6 & 10 & 5.4 \\
\hline 4 & $20 / 06 / 18$ & $4: 15: 55$ & $9: 45: 55$ & $27.26^{\circ} \mathrm{N}$ & $87.91^{\circ} \mathrm{E}$ & 3.4 & 5 & Nepal \\
\hline
\end{tabular}




\begin{tabular}{|c|c|c|c|c|c|c|c|l|}
\hline 5 & $05 / 06 / 18$ & $1: 34: 42$ & $7: 04: 42$ & $29.73^{\circ} \mathrm{N}$ & $81.58^{\circ} \mathrm{E}$ & 4.5 & 10 & Nepal \\
\hline 6 & $19 / 10 / 18$ & $19: 57: 23$ & $1: 27: 23$ & $28.57^{\circ} \mathrm{N}$ & $82.88^{\circ} \mathrm{E}$ & 4.0 & 10 & Janakpur, Nepal \\
\hline 7 & $11 / 11 / 18$ & $7: 07: 28$ & $12: 37: 28$ & $29.83^{\circ} \mathrm{N}$ & $80.53^{\circ} \mathrm{E}$ & 4.7 & 10 & $\begin{array}{l}\text { Nepal-India Border Region, } \\
\text { Pithoragarh, India }\end{array}$ \\
\hline 8 & $22 / 12 / 18$ & $23: 21: 09$ & $4: 51: 09$ & $27.64^{\circ} \mathrm{N}$ & $85.41^{\circ} \mathrm{E}$ & 4.0 & 24 & $\begin{array}{l}\text { Jorpati, Kathmandu, } \\
\text { NaikapPuranobhanjyan, Nepal }\end{array}$ \\
\hline
\end{tabular}

Table-5 Data collected from Nepal for year 2019

\begin{tabular}{|c|c|c|c|c|c|c|c|l|}
\hline S.no & Date & Time & Time & Longitude & Latitude & Magnitude & Depth & \multicolumn{1}{|c|}{ Region } \\
\hline 1 & $22 / 01 / 19$ & $16: 45: 28$ & $22: 15: 28$ & $27.2635^{\circ} \mathrm{N}$ & $86.921^{\circ} \mathrm{E}$ & 4.3 & 10 & $\begin{array}{l}\text { North west of Bhojpur, } \\
\text { Nepal }\end{array}$ \\
\hline 2 & $18 / 03 / 19$ & $3: 16: 34$ & $8: 46: 34$ & $27.63^{\circ} \mathrm{N}$ & $85.16^{\circ} \mathrm{E}$ & 4.1 & 10 & $\begin{array}{l}\text { Kathmandu, Kirtipur, } \\
\text { Nepal, Kolkata, India }\end{array}$ \\
\hline & & & & & & & & $\begin{array}{l}\text { Okhaldhunga, } \\
\text { Kathmandu, } \\
\text { Mahangkal (Nepal }\end{array}$ \\
\hline 4 & $24 / 04 / 19$ & $0: 44: 23$ & $6: 14: 23$ & $27.92^{\circ} \mathrm{N}$ & $85.05^{\circ} \mathrm{E}$ & 4.8 & 9 & \\
\hline 5 & $16 / 04 / 19$ & $6: 50: 26$ & $12: 20: 26$ & $28^{\circ} \mathrm{N}$ & $84.76^{\circ} \mathrm{E}$ & 4.5 & 10 & $\begin{array}{l}\text { Thapachowk, Janakpur, } \\
\text { Nepal, Siliguri, India }\end{array}$ \\
\hline 6 & $14 / 04 / 19$ & $22: 42: 12$ & $4: 12: 12$ & $29.6463^{\circ} \mathrm{N}$ & $81.4054^{\circ} \mathrm{E}$ & 4.0 & 29.1 & $\begin{array}{l}\text { 62km NE of Dipayal, } \\
\text { Nepal }\end{array}$ \\
\hline 7 & $01 / 04 / 19$ & $15: 02: 39$ & $20: 32: 39$ & $28.98^{\circ} \mathrm{N}$ & $81.69^{\circ} \mathrm{E}$ & 4.1 & 10 & $\begin{array}{l}\text { Thapachowk, Janakpur, } \\
\text { Nakhu, Nepal }\end{array}$ \\
\hline 8 & $25 / 05 / 19$ & $5: 17: 52$ & $10: 47: 52$ & $27.67^{\circ} \mathrm{N}$ & $86.28^{\circ} \mathrm{E}$ & 4.6 & 10 & Nepion \\
\hline
\end{tabular}

The above tables from 1 to 5 of Nepal represents raw data from the meteorology department of past 5 years where each row represents if the earthquake as an event happened or $\operatorname{not}(1$ or 0$)$.

The demographic location ,temperature, magnitude, depth etc are considered as a record of earthquakes that make up the database to study a pattern based on the range of depth and magnitude. These tables have contributed on understanding the pattern and consequences of specified regions. The occurrences of earthquake analysis through datadriven earthquake tables analysis will furnish insights of seismic waves movement having different temperatures into the systematics of the earthquake occurrence.

\section{Result and Discussion}

This paper has first checked the big data for abnormal observations or check for any kind of errors in data collection which can be observed by producing incorrect output. The sudden shift in the series or change in a trend or pattern must be taken in account.

There is a clear upward trend in the following time series including magnitude and depth as a main parameter. As the data values increases over the span of time and depth a little curve is observed on the data values taken and analyzed. A common pattern is a rise and fall in the data values observed on parameters like magnitude and depth that repeats regularly over the same time period. For example, the magnitude of earthquakes islow where the longitude is from $80.53^{\circ} \mathrm{E}$------to $87.86^{\circ} \mathrm{E}$ and latitude is from $27.76^{\circ} \mathrm{N}$-----increase as the depth increase. Seasonal patterns as always have a fixed and known period thus it is found in most of the cases the occurrences of earthquake is during daytime. In contrast, cyclic movements are cycles of rising and falling data values of magnitude and depth that do not repeat at regular a interval which signifies the extreme occurrences of earthquakes with longer duration and sometimes change in pattern. If there is a less variation in magnitude and depth an additive feature is observed during the occurrences of earthquakes. Like time and region play an important role.

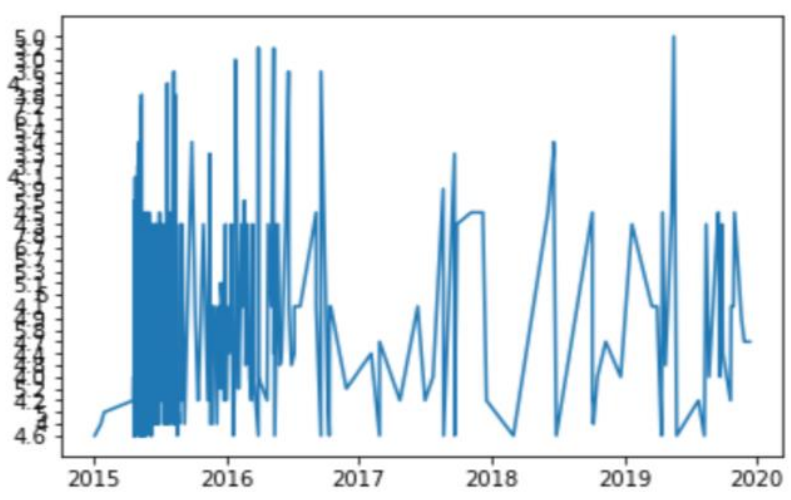

Graph -1 Graphical presentation on magnitude 


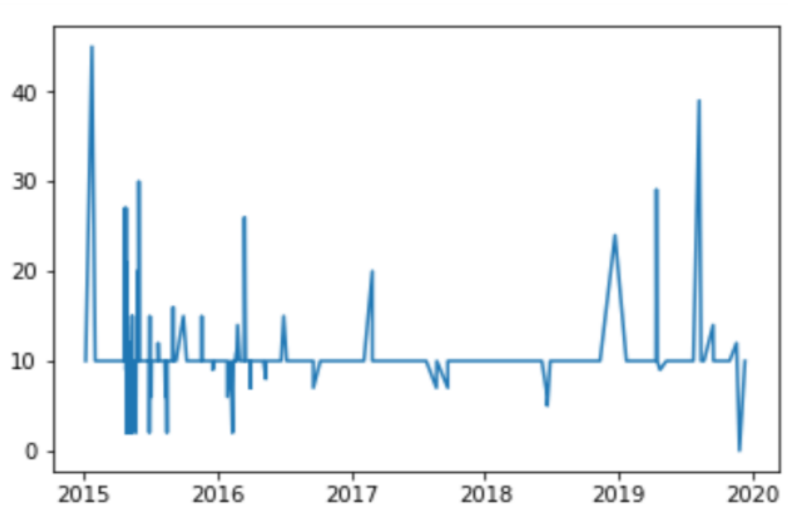

Graph-2 Graphical presentation on depth

Time-Series Prediction

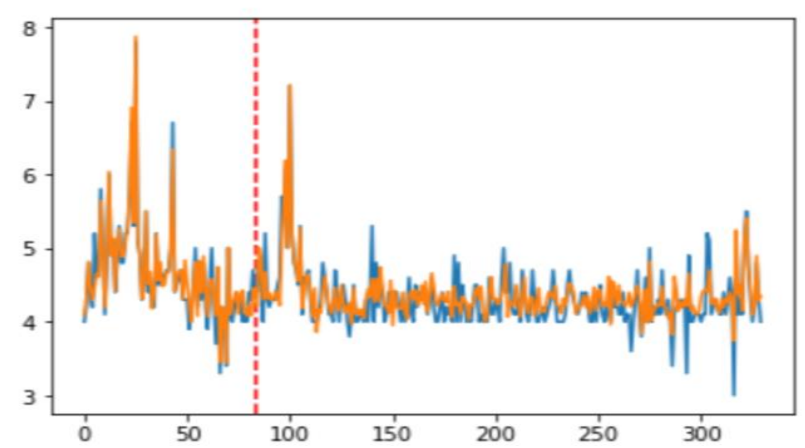

Graph -3 Graphical presentation time series prediction using depth and magnitude
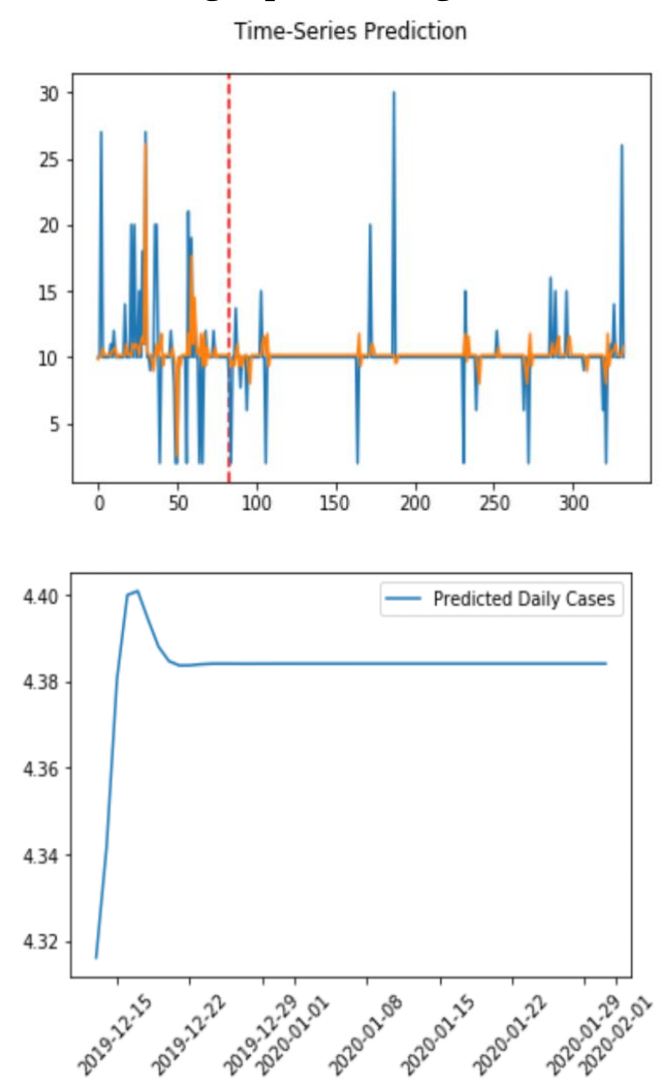

Graph- 4 Graphical presentation time-Series prediction to take decision
The generated graph by Python programming accommodates the data records to compare parameters plots for the different interval such as variations in day, month and year.

The cold and hot temperature categorized parameter in dataset considered for 5 years are combined for year and drawn a line plot for each year for direct comparison. The groups are then enumerated and the observations for each year are enumerated stored as tuple in a Data Frame and considered as a new record. Each tuple of the new record has given the correlation of depth and magnitude having different ranges. The correlation further absorbed the common pattern to draw a valid conclusion on occurrences of earthquake. The line plot of the graph expresses as a median based on observations and outliers are shown with either deep rise or fall side by side for comparison studies. The horizontal axis is used to plot the date or time increments, and the vertical axis is used to plot the parameters which are variable like magnitude and depth and the horizontal axis corresponds temperature, date and time variation which show cyclic pattern.

\section{Conclusions}

In this study, historical data of earthquake collected for five years of Nepal is used. Firstly, the big data is filtered to get an applicable and required data to apply the Time series data mining concept. Using python programming LSTM layers model is developed to study the correlation of location, depth and magnitude for predicting earthquake. This LSTM model produces the graphs showing the result that the neural network model provides higher forecast accuracy. As neural network captures non-linear relationship than statistical methods. This study has shown there is a very strong connection of seismic waves in particular a region having a correlation of magnitude and depth and thus showing a probability of occurrences of earthquake. The earth's crust takes place due to seismic wave propagation which can be measured by finding the relationship of depth, magnitude and location in turn predicts the occurrences of earthquake. To predict earthquakes earlier are been very important to reduce the destruction. Based on this study expert decision systems can be developed analyzing time series pattern on seismic wave movements. In this study, the five years earthquake occurrences in Nepal using seismic time series data, estimates local magnitude, depth the coordinates of earthquake prediction to give an estimation of a location of occurrences of a probability of earthquake. A decision system will be the best incorporating this neural network model to get the best prediction.

Declaration I, Sumita Mukherjee am working hard with metrology and seismology department of Nepal towards collection of bonafied data of last five years. The data mining analysis is studied thoroughly and its concept, application and usage for prediction. Firstly, I would like to thank my guide 
Dr. Prinima Gupta, and co -guide Prof. Felix Musau for their guidance and support. I can't thank you both enough for the constant support and guidance, discussion and help to solidify my ideas to write this paper. I would like to extend my thanks to my dear colleagues Ms. Carolyne, Ms. Maryanne Gichuhi, and friend Ester for co- operating and motivating me. I also grateful to my child Subhaditya Mukherjee for your service.

\section{References}

[1] Md. Zakir Hossain, Md Nasim Akhtar, R.B. Ahmed, A dynamic K-means clustering for data mining, Indonesian Journal of Electrical engineering and computer science 2013(2):521,2019 DOI: 10.11591/ijeecs.v13.i2.pp521-526

[2] Hashemi, M., \& Alesheikh, A. Spatio-temporal analysis of Tehran's historical earthquakes trends. In Proceedings of Advancing Geoinformation Science for a Changing World (pp. 3-20). Utrecht, Netherlands: Springer. 2011.

[3] Khawaja Asim, Adan Idiris, Talat Iqbal, Francisco Alvarez, Earthquake prediction model using support vector regressor and hybrid neural networks Centre for Earthquake Studies, National Centre for Physics, Islamabad, Pakistan, Department of Science, Pablo de Olavide University, Seville, Spain DOI: 10.1371/journal.pone.0199004 2018

[4] Ebel, J. E., Chambers, D. W., Kafka, A. L., \& Baglivo, J. A. Non-poissonian earthquake clustering and the hidden Markov model as bases for earthquake forecasting in California

[5] Mark last, Nitzan Rabinowitz, Goldewn Leonard,Predicting the Maximum Earthquake Magnitude from Seismic Data in Israel and Its Neighboring Countries PLoS ONE 11(1):e0146101 DOI: 10.1371/journal.pone.0146101,2016

[6] Pouria hajikhodaverdikhan,Shamshirband Shahaboddin, Nazri Mousa,Chau Kwok-wing Earthquake prediction with meteorological data by particle filter-based support vector regression, Engineering Applications of Computational Fluid Mechanics Journal, https://doi.org/10.1142/S0129065707000890 2007.

[7] Ashif Panakkat, Hojjat Adeli Neural Network Models for Earthquake Magnitude Prediction Using Multiple Seismicity Indicators, International Journal of Neural Systems, https://doi.org/10.1080/19942060 2010

[8] Sankar Kumar Nath, Suman Mandal, Manik Das Adhikari, Soumya Kanti Maiti, A unified earthquake cataloguefor South Asia covering the period 19002014,Springer,Natural Hazards, DOI: 10.1007/s11069016-2665-6 2017

[9] Rehmamn, Khaista, Burton,Paul W, Seismicity and seismic hazard parameters in and around Pakistan, Journal of Seismology, Volume 24, Issue 3, p.635-653, DOI: 10.1007/s10950-020-09917-4 2020

[10] Kasarapu Ramani,Sree Vidyanikethan PERFORMANCE OF CLASSIFICATION
ALGORITHMS WITH WEKA AND SPARK TOOLS Volume 5, Issue 1 JETIR (ISSN-2349-5162) JETIR1801119,Journal of Emerging Technologies and Innovative Research (JETIR) 2018

[11] Pushan Dutta A Specialized Hardware Based Design for Earthquake Warning Design and Identification of the Sensing Area Module in Remote Areas: A Practical Approach, The Open Electrical \& Electronic Engineering Journal 2(3):9-18 DOI: 10.20431/2454 9436.0203002 2016

[12] LAWAL S.N, ANANDE T.J, GENGER T.K. DATA MINING USING WEKA TOOL FOR INTERNALLY DISPLACED PERSONS DATASET IN NORTHEASTERN NIGERIA International Journal of Advance Engineering and Research Development Volume 4, Issue 7, July-2017 @IJAERD-2017

[13] Maria Moustra, Marios Avraamides, Chris Christodoulou, Artificial neural networks for earthquake prediction using time series magnitude data or Seismic Electric Signals Expert Systems with Applications 38(12):15032-15039

DOI: 10.1016/j.eswa.2011.05.043,2011

[14] Ashif Panakkat,Hojjat Adeli, NEURAL NETWORK MODELS FOR EARTHQUAKE MAGNITUDE PREDICTION USING MULTIPLE SEISMICITY INDICATORS

https://doi.org/10.1142/S0129065707000890DOI: 10.1 016/j.eswa.2011.05.043 2016

[15] S.Narayanakumar, K.Raja, A BP Artificial Neural Network Model for Earthquake Magnitude Prediction in Himalayas, India, Circuits and Systems 07(11):34563468, DOI: $10.4236 /$ cs.2016.711294,2016

[16] S. Niksarlioglu, and F. Kulahci, An Artificial Neural Network Model for Earthquake Prediction and Relations between Environmental Parameters and Earthquakes, World Academy of Science, Engineering and Technology International Journal of Geological and Environmental Engineering Vol:7, No:2, 2013

[17] Vijayasankari S,Indhuja P, Earthquake Prediction based on Spatio - Temporal Data Mining Approach International Journal of Scientific \& Engineering Research Volume 9, Issue 4, April-2018 1573 ISSN 2229-5518 IJS9ER , 2018

[18] Mr. Dharmesh Dhabliya, Dr.S.A.Sivakumar. (2019). Analysis and Design of Universal Shift Register Using Pulsed Latches . International Journal of New Practices in Management and Engineering, 8(03), 10 - 16

[19] Ratiranjan Jena, Biswajeet Pradhan, Ghassan Beydoun, Nizamuddin Ardiansyan, Hizir Sofyan,Integrated model for earthquake risk assessment using neural network and analytic hierarchy process: Aceh province, Indonesia,Geoscience

Frontiers,https://doi.org/10.1016/j.gsf.2019.07.006, Volume 11, Issue 2, March 2020, [19] José Manuel Azevedo1 , Rui Almeida2 , Pedro Almeida3, Using Data Mining with Time Series Data in Short-Term Stocks Prediction: International Journal of Intelligence Science, 176-180 http://dx.doi.org/10.4236/ijis.2012 